\title{
Human rights, property and the Recovery of Medical Costs for Asbestos Diseases (Wales) Bill in the Supreme Court
}

Frankie McCarthy*

The Recovery of Medical Costs for Asbestos Diseases (Wales) Bill was referred to the Supreme Court by the Counsel General for Wales for a determination of its legislative competence. ${ }^{1}$ Two potential issues arose: first, whether the Bill purported to legislate on matters which had not been devolved to the Welsh Assembly; and second, whether it contravened Article 1 of the First Protocol to the European Convention on Human Rights (A1P1). The court was unanimous in determining that the Bill was incompetent on both grounds, although the minority (Lord Thomas and Lady Hale) reached that conclusion on considerably narrower grounds that the majority (Lords Mance, Hodge and Neuberger.) The decision has relevance for the proposed Recovery of Medical Costs for Asbestos Diseases (Scotland) Bill, in respect of which the initial consultation closed shortly after this judgment was handed down. ${ }^{2}$ This note summarises the findings of the Supreme Court, before discussing the A1P1 implications of the decision for the potential Scottish Bill.

\section{A: THE WELSH BILL}

Where a person in the UK pays compensation in respect of physical or psychological injury to another, they also become liable for NHS charges in relation to the treatment of that injury. ${ }^{3}$ The Bill proposed creation of a similar liability in respect of Welsh NHS charges for treatment of asbestosrelated diseases. Section 2 sought to impose liability on any person who paid compensation for an asbestos-related disease. Such "compensators" would typically be employers who had negligently exposed the sufferer to asbestos during his working life. Section 14 proposed that where the payment made by a compensator was covered by an insurance policy, the policy was to be treated as covering liability for NHS charges. This would have applied to policies issued both before and after the section came into force.

In the judgment, the majority interpreted the legal effect of these provisions somewhat differently from the minority. The majority view, set out by Lord Mance, was that the Bill would impose a new quasi-tortious statutory duty of care on compensators, together with a new contractual

\footnotetext{
*Senior Lecturer in Private Law, University of Glasgow.

${ }^{1}$ Recovery of Medical Costs for Asbestos Diseases (Wales) Bill: Reference by the Counsel General for Wales [2015] UKSC 3.

${ }^{2}$ The proposed Bill and consultation document are available at http://www.scottish.parliament.uk/parliamentarybusiness/Bills/85164.aspx.

${ }^{3}$ Health and Social Care (Community Health and Standards) Act 2003, s.150.
} 
liability on the insurers of those compensators. ${ }^{4}$ The minority view set out by Lord Thomas considered that, since the cost of medical care is an established head of recovery in a compensation claim, the Bill imposed no new liability on compensators. Rather, it removed the benefit formerly enjoyed by compensators of that cost being met by the state - a benefit that compensators could have had no legitimate expectation would continue. The "machinery" for the collection of these costs placed responsibility directly on compensators, rather than on those in receipt of treatment who might then recover the costs from compensators, in order to maximise efficiency and minimise stress for sufferers. ${ }^{5}$ The same result obtained for insurers to the extent that they would always have been liable to indemnify costs arising under this head of recovery. However, the Bill proposed that insurers be made liable for the full value of NHS charges, without regard to the fact that an insurance policy would usually restrict liability by way of deductibles and a policy limit. To the extent that these restrictions were ignored by the Bill, the minority accepted that a new contractual duty was being placed on insurers. ${ }^{6}$

These differences in conceptualisation of the effect of the Bill are essential to an understanding of the findings of the Court.

\section{B: COMPETENCE UNDER GOWA, ss108(4) AND (5)}

The Government of Wales Act 2006, ss108 and 109, read with sch 7, circumscribe the matters on which the Welsh Assembly may competently legislate. The relevant matter for the purposes of the Bill is the "organisation and funding of national health service." The majority took the view that, although it might be possible to read this phrase as conferring power on the Welsh Assembly to raise monies for NHS purposes, ${ }^{7}$ there would have to be a close connection between the charges applied and the service received, as with the case of prescription charges where the recipient of the medication was charged for its cost. The link here between increased statutory and contractual duties on compensators and insurers and treatment of asbestos-related diseases was too tenuous to fall within this definition, particularly when the Bill did not provide for any funds raised to be hypothecated to related treatment services. ${ }^{8}$ On that basis, the Bill fell outside the legislative competence of the Assembly.

The minority were more firmly of view that the Assembly had competence to enact legislation which makes provision for NHS treatment charges for asbestos-related diseases, ${ }^{9}$ and indeed had done so in this case. Rather than imposing charges directly on the sufferer, the

\footnotetext{
4 Para 6.

${ }^{5}$ Para 77; also paras 96-102.

${ }^{6}$ Para 133 and 138.

${ }^{7}$ Para 24.

${ }^{8}$ Paras 26-28.

${ }^{9}$ Para 95.
} 
"machinery" of the Bill operated to impose them on the compensator, but this could not take the provisions beyond the competence of the Assembly. ${ }^{10}$ The extension of the liability on insurers resulting from failure to take account of deductibles and policy limits did, however, exceed the powers of the Assembly, since such costs would not already have been recoverable in a compensation claim. To that extent, the minority also found the Bill to fall outside the legislative competence of the Assembly. ${ }^{11}$

\section{C: COMPLIANCE WITH A1P1}

Having already determined that the Bill exceeded the legislative competence of the Assembly under the first head of argument, it was not necessary for the Court to consider the human rights issue, but helpfully it decided to do so nevertheless. A1P1 contains the right to peaceful enjoyment of possessions. All five judges accepted that the A1P1 rights of compensators and insurers were engaged by the Bill, since their possessions in the form of capital funds would be directly impacted by having to make payments in respect of NHS charges. The question then became whether this interference with property rights could be justified. Lord Mance identified four stages in the process of review of legislative measures which engage A1P1: ${ }^{12}$

(i) Whether there is a legitimate aim which could justify a restriction of the relevant protected right;

(ii) Whether the measure adopted is rationally connected to that aim;

(iii) Whether the aim could have been achieved by a less intrusive measure;

(iv) Whether, on a fair balance, the benefits of achieving the aim by the measure outweigh the disbenefits resulting from the restriction of the relevant protected right.

He stressed that the court will accept the legislature's judgment as to the existence of a legitimate aim at stage (i) review, unless that judgment is manifestly without reasonable foundation. However, this latitude does not extend to stage (iv), where the level of scrutiny required by the Court is higher. The question at stage (iv) is whether the measure achieves a fair and proportionate balance between the public interest pursued and the private interests affected. Although the views of the legislature may still carry significant weight in the balancing exercise, private interests must be given similar consideration, and the court may be particularly well placed to evaluate those in the context of a particular case. ${ }^{13}$

\footnotetext{
${ }^{10}$ Para 100-101.

11 Para 132-133.

${ }^{12}$ Para 45.

${ }^{13}$ Para 52.
} 
An additional concern arose here given the partially retrospective nature of the legislation. Although the provisions of the Bill would only apply in respect of compensation payments made after its entry into force, those payments related to negligent acts, and insurance policies concluded in respect of that negligence, years or decades earlier. In other words, liabilities accrued prior to the introduction of the Bill would be expanded by the Bill. Special justification is required for retrospectivity in the balancing exercise undertaken at stage (iv).

The majority focused on stage (iv) of the review process in its decision, ultimately determining that a fair balance had not been struck. The Bill would create significant unforeseen and unforeseeable new liabilities for compensators and insurers which they had no opportunity to assess, rate or make reserves to cover. ${ }^{14}$ It could also be distinguished from the Damages (Asbestos-related Conditions) (Scotland) Act 2009, by which the Scottish Parliament provided that pleural plaques, plural thickening and asbestosis were actionable wrongs, ${ }^{15}$ and which was found by the Supreme Court to comply with A1P1 in Axa General Insurance Ltd, Petitioners. ${ }^{16}$ That legislation operated primarily to clarify the law, with only a consequential effect on insurers. Additionally, the AXA legislation aimed primarily to benefit victims. Here, the primary benefit was to the state.

Although the minority ultimately agreed that A1P1 had been contravened, it again did so on a much narrower basis. Lord Thomas emphasised that the proposed legislation must be viewed in the Welsh social and economic context, summarising the particular challenges faced by the Welsh NHS given the historical concentration of heavy industry in Wales and the high incidence of occupational disease which has resulted. ${ }^{17}$ The Bill was found to have a legitimate aim in withdrawing from negligent employers the benefit of state delivery of treatment services, which was particularly necessary given the increasing financial pressure on the Welsh NHS. ${ }^{18}$ This aim was in the interests of social justice as determined by the Welsh legislature. It would not be appropriate for the Court to substitute its judgment of social justice from that of the democratically elected Assembly. ${ }^{19}$ The social and economic context was considered to provide the necessary special justification for the retrospective elements of the provision. ${ }^{20}$ The minority also gave greater weight to the social justice benefits to be derived from the measure in the balancing exercise, ultimately determining that the Bill was proportionate to the extent that employers were affected. ${ }^{21}$ As before, however, the imposition of

\footnotetext{
${ }^{14}$ Para 69.

${ }^{15}$ Para 63.

16 [2011] UKSC 46.

17 Para 106.

${ }^{18}$ Paras 107-8.

19 Para 124.

${ }^{20}$ Para 113.

${ }^{21}$ Para 127-8.
} 
new liabilities on insurers which failed to take account of deductibles and policy limits was considered disproportionate, meaning the Bill as a whole contravened A1P1. ${ }^{22}$

\section{D: IMPLICATIONS FOR THE PROPOSED SCOTTISH LEGISLATION}

In January 2015, Stuart McMillan MSP proposed the introduction of a Bill making similar provision for the recovery of NHS treatment costs for asbestos-related diseases in Scotland. The aim of the proposed Recovery of Medical Costs for Asbestos Diseases (Scotland) Bill would be to: ${ }^{23}$

Enable Scottish Ministers to recover, from anyone responsible for paying compensation to a victim of asbestos-related disease, certain costs incurred by the NHS in Scotland in providing care and treatment to that victim.

The consultation paper suggests a Bill written in terms which closely mirror the Welsh legilsationproposal, with a direct obligation on compensators to pay NHS charges and a specific statutory extension of insurance cover in relation to these costs.

Given the findings of the Supreme Court outlined above, an A1P1 challenge to any Bill which results seems inevitable. Some of the concerns that animated the majority in carrying out the balancing exercise - in particular, the very short transitional period proposed prior to the introduction of the legislation, which gave insurers little time to adjust - could certainly be ameliorated in Scotland. However, so long as any legislation is conceptualised as placing significant new liabilities on compensators and insurers, it will be difficult for it to satisfy the proportionality test. The alternative interpretation put forward by the minority, although interesting, is hard to see as anything other than a back-formation. For all that the Bill could be construed in some sense as removing a benefit, the words speak clearly of imposing a liability. Legislation which actually imposed liability for NHS charges on sufferers of asbestos-related diseases, even if made subject to the ability of sufferers to recover from compensators, would give rise to A1P1 issues of its own, in addition to being a deeply unattractive proposition for anyone who values the current model of the NHS as a service free at the point of use.

Of course, sufferers of asbestos-related diseases, along with all other working people in the UK, have already paid for NHS treatment through income tax and national insurance. In identifying the beneficiary of the Welsh Bill as "the state", it is perhaps easy to lose sight of the fact that the state includes all of us who pay or have paid into the public coffers over the years. A bigger question arises

\footnotetext{
22 Para 139.

${ }^{23}$ Consultation on the Proposed Recovery of Medical Costs for Asbestos Diseases (Scotland) Bill, p1.
} 
here, particularly in light of the increasing number of A1P1 claims brought by legal persons, ${ }^{24}$ about whether the property right was ever intended to give the same protection to what Michael Robertson terms "powerful property" - shortly put, that which gives the owner power over others, as in the case of insurance reserves - as to "non-powerful property", like a house, which is of value principally its owner alone. ${ }^{25}$ Although not an easy question to answer, the current author's contention is that the check placed by the A1P1 rights of the insurance lobby here on the pursuit of the significant social justice aims - righting the wrongs done to those negligently exposed to asbestos and funding the NHS - cannot be what the drafters of the Convention had in mind when including this particular protection.

${ }^{24}$ Recent examples of successful A1P1 challenges in the UK include Department of Energy and Climate Change v Breyer Group [2015] EWCA (Civ) 408, Ofgem (Gas and Electricity Markets Authority) v Infinis [2013] EWCA (Civ) 70 and Whyte \& Mackay v Blyth \& Blyth Consulting Engineers [2013] CSOH 54.

${ }^{25}$ M. Robertson, 'Property and ideology' (1995) Canadian Journal of Law and Jurisprudence 275-296, building on the foundational work by M. Cohen, 'Property and sovereignty’ (1927) 13 Cornell L Q 8-30. 